This item was submitted to Loughborough's Research Repository by the author.

Items in Figshare are protected by copyright, with all rights reserved, unless otherwise indicated.

\title{
Control over the shell thickness of core/shell drops in three-phase glass capillary devices
}

PLEASE CITE THE PUBLISHED VERSION

http://www.constableandsmith.com/UKColloids2011/Programme and Abstracts Colloids 2011.pdf

PUBLISHER

UK Colloids 2011

VERSION

VoR (Version of Record)

LICENCE

CC BY-NC-ND 4.0

\section{REPOSITORY RECORD}

Vladisavljevic, Goran T., Ho Cheung Shum, and David A. Weitz. 2012. "Control over the Shell Thickness of Core/shell Drops in Three-phase Glass Capillary Devices”. figshare. https://hdl.handle.net/2134/10710. 


\title{
Control over the shell thickness of core/shell drops in three-phase glass capillary devices
}

\author{
[Goran T. Vladisavljević ${ }^{1}$, Ho C. Shum ${ }^{2}$, David A. Weitz ${ }^{3}$ ] \\ ${ }^{1}$ Department of Chemical Engineering, Loughborough University, Loughborough, \\ LE11 3TU, UK; ' ${ }^{2}$ Department of Mechanical Engineering, University of Hong Kong, \\ Hong Kong; ${ }^{3}$ Department of Physics, Harvard University, MA 02138, USA.
}

\section{G.Vladisavljevic@lboro.ac.uk}

\section{Abstract:}

Core/shell drops find uses as templates for the production of core/shell particles and functional vesicles, such as liposomes, polymerosomes and colloidosomes. In this work, monodisperse core/shell drops with a controllable shell thickness were produced using microcapillary device shown in Figure 1. This device consists of two circular capillaries with a tapered end inserted into a square capillary. Milli-q water was supplied through the injection tube with an orifice diameter of $44 \mu \mathrm{m}$. A mixture of $2 \%$ (w/w) Dow Corning 749 Fluid in $10 \mathrm{cP}$ PDMS was supplied as a middle fluid through the square capillary in the same direction. The continuous phase was an aqueous solution containing $2 \%(\mathrm{w} / \mathrm{w})$ poly(vinyl alcohol) and $40 \%$ glycerol. The continuous phase liquid was supplied from the opposite side through the square capillary and all three liquid streams were forced into the collection tube with an orifice diameter of $115 \mu \mathrm{m}$. It resulted in the rupture of coaxial jet composed of inner and middle fluid and the formation of discrete core/shell drops. In order to prevent wetting of the injection tube with water, the tapered section of the injection tube was rendered hydrophobic with octadecyltrimethoxysilane. The shell thickness ranged from several $\mu \mathrm{m}$ to several tens of $\mu \mathrm{m}$ and was controlled by adjusting the ratio of the middle liquid flow rate to the inner liquid flow rate (Fig. 1). The drop generation frequency was in the range from 1,000 to $10,000 \mathrm{~Hz}$ and the drop diameter varied between 60 and $150 \mu \mathrm{m}$. The drop size and generation frequency were controlled by changing the flow rate of the continuous phase in the range from 10 to $45 \mathrm{~mL} \mathrm{~h}^{-1}$.
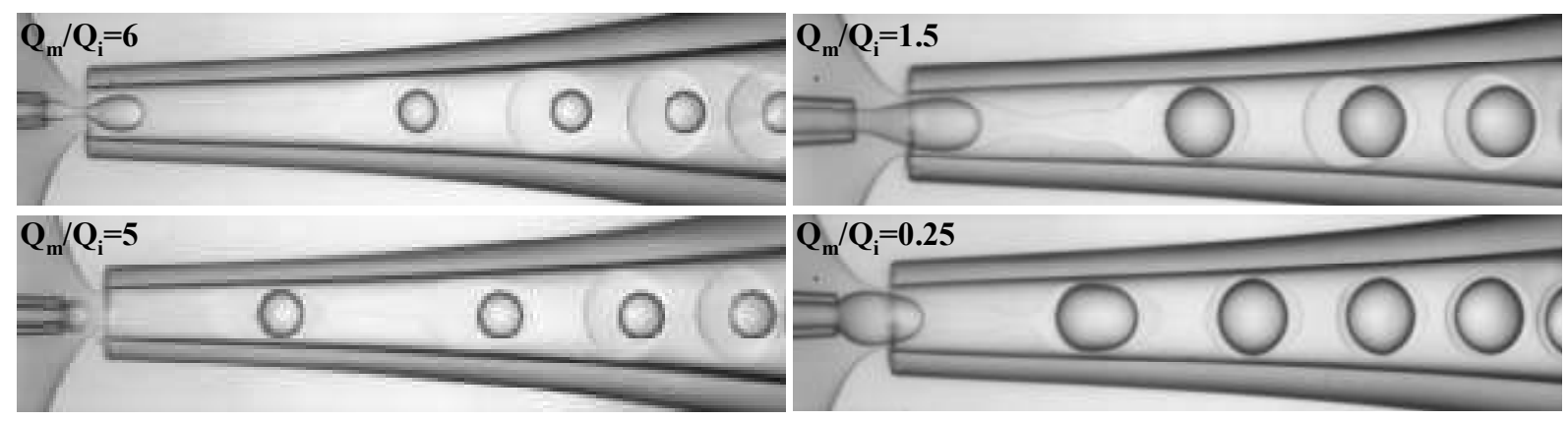

Fig. 1. Control over the shell thickness of core/shell droplets in glass capillary devices by changing the ratio of the middle fluid flow rate $Q_{m}$ to the inner fluid flow rate $Q_{i}$. The orifice size of the injection tube was $44 \mu \mathrm{m}$.

\section{Acknowledgment}

The work was supported by the Engineering and Physical Sciences Research Council (EPSRC) of the United Kingdom (grant reference number: EP/HO29923/1). 